\title{
Background stressors and deliberate self-harm
}

\section{Prospective case note study in southern Ireland}

\author{
AIMS AND METHOD \\ In this study we aimed to identify \\ negative life events, especially \\ those associated with repetition, \\ in the background histories of \\ patients in a 2-year prospective \\ monitoring study of hospital-treated \\ deliberate self-harm (DSH). Thematic \\ analysis of the narratives recorded \\ during assessment was used to
}

\author{
produce general categories of life \\ events. \\ RESULTS \\ In 3031 DSH episodes ( $n=2287$ indivi- \\ duals), women reported more life \\ events than men. Family and inter- \\ personal problems were most com- \\ monly reported. Reporting a \\ dysfunctional family of origin, a \\ history of sexual abuse and the
}

\begin{abstract}
imprisonment of self or other were associated with repetition retrospectively and prospectively.

\section{CLINICAL IMPLICATIONS}

The background history of patients who harm themselves should be explored routinely on assessment in order to help establish risk of repetition and to determine appropriate follow-up.
\end{abstract}

The reasons why people engage in deliberate self-harm (DSH) tend to be complex and multiple. The immediate precipitants that people cite for harming themselves are well-described and tend predominately to involve interpersonal conflict and loss (Heikkinen et al, 1994; Rubenowitz et al, 2001). However, other factors, not necessarily identified as immediately relevant by the person, may also predispose him or her to self-harm when in difficulties. These include life events that can occur at any time during the life cycle, including early childhood, and have long-standing effects on the personal development of the subject (Dube et al, 2001) We aimed to describe and classify the life events, not directly precipitating the episode, reported by a large consecutive series of patients treated in hospital for DSH.

\section{Method}

\section{Subjects}

Between 1995 and 1997, the National Suicide Research Foundation administered the two Irish centres in the World Health Organization/Euro Multicentre Study on Suicidal Behaviour (Platt et al, 1992). Located in the south-west of the country, the catchment area included the cities of Cork and Limerick, and contained $24 \%$ (863 709) of the Irish population, almost half of whom live in urban settings (Central Statistics Office, 1997). Ten general hospitals with accident and emergency room facilities, five psychiatric hospitals and three prisons were monitored by independent data collectors. Every case of DSH was identified using the definition developed by the Working Group of the World Health Organization/Euro Multicentre Study (Platt et al, 1992).

\section{Preliminary thematic analysis}

During the period January to June 1995, narratives regarding each subject's life history, where available, were transcribed from hospital case notes. Once such information had been recorded for 200 cases, the text was read separately by H.S.K. and M.O.S. Following clinical discussion, 20 underlying themes regarding past stressors and life events were identified and coded into general categories. This process followed the 'grounded' approach first recommended by Glaser \& Strauss (1967). These categories then constituted a coding frame for the narratives that were transcribed over the following 2year period (July 1995-June 1997). Throughout this period, routine research meetings were held to discuss coding disagreements and to monitor the suitability of the coding frame. As a consequence of these meetings, the coding frame was revised as new categories 'surfaced' and original categories were merged, until eventually there were 21 categories in total (Lincoln \& Guba, 1985).

\section{Statistical analysis}

Chi-squared and Mann-Whitney $U$ tests were used, as appropriate, to compare those who were asked about past stressors and life events in their assessment and those who were not asked across a range of characteristics relevant to the individual and his or her suicidal behaviour. Chi-squared tests were also used to compare the male and female prevalence of the various categories of life events. Separate logistic regression analyses were carried out to estimate the association between each category of life event and the risk of the individual harming him- or herself repeatedly, with adjustment for age and gender. Effect modification by gender was also examined. Those categories indicated as being significantly associated with repetition of DSH were then entered with age and gender into a single logistic regression model to determine which life event categories were significantly and independently associated with DSH repetition in these patients. A similar series of logistic regression analyses were carried out to assess the risk of further repetition during the study period, with 
adjustment for the effects of previous DSH, age and gender.

original

papers

\section{Results}

\section{Subjects}

Over the 2-year period, there were 3031 episodes of hospital-treated DSH by 2287 individuals; 1047 men (46\%) and 1240 women (54\%). The 1943 patients (85\%) whose previous history of DSH was known included 770 (40\%) who had harmed themselves before and 1773 $(60 \%)$ for whom this was their first recorded act of DSH. The prevalence of previous DSH was similar for men and women ( $41 \%$ and $38 \%$, respectively). The opportunity to discuss life events as part of their assessment was given to two-thirds of all patients $(n=1518)$. Table 1 compares those questioned about life events with those who were not questioned across a range of characteristics. There were fewer men among the patients asked about life events in their assessment $\left(\gamma^{2}=13.235\right.$, d.f. $\left.=1, P<0.001\right)$.

\section{Prevalence of background stressors}

Of those asked at the time of their index act, 12\% reported no background stressors, $48 \%$ discussed one event, $22 \%$ two events and $18 \%$ three or more events. The maximum number of seven stressors was reported by two female patients. On average, women reported more life events than men did (Mann-Whitney $U=266386.5$, $P<0.001)$, irrespective of whether the index act was a first or repeat act of DSH.

Table 2 shows the prevalence of the 14 most frequently reported life event categories. For both genders, the most commonly reported categories of life event related to interpersonal difficulties. Women more often reported family conflict/current problems $\left(\chi^{2}=4.242\right.$, d.f. $\left.=1, P<0.05\right)$, pregnancy-related problems $\left(\chi^{2}=21.439\right.$, d.f. $\left.=1, P<0.001\right)$ and a history of abuse, both sexual $\left(\chi^{2}=27.605\right.$, d.f. $\left.=1, P<0.001\right)$ and physical $\left(\chi^{2}=6.957\right.$, d.f. $\left.=1, P<0.05\right)$. Legal $/$ judicial problems were more often cited by men $\left(\chi^{2}=16.678\right.$, d.f. $\left.=1, P<0.001\right)$, as was imprisonment of self or other $\left(\chi^{2}=16.293\right.$, d.f. $=1$, $P<0.001)$

\section{Retrospective repetition}

Table 2 indicates that five categories of self-reported life events were significantly associated with a previous history of DSH. Those who reported work or school problems were less likely to have a history of previous self-harm. Reporting problems related to a dysfunctional family of origin, a history of either sexual or physical abuse and imprisonment of self or other was associated with an increased prevalence of DSH. There was no significant effect modification by gender except in the case of those with a history of physical abuse. Such a history was associated with increased prevalence of DSH in women (odds ratio (OR) $=3.03,95 \%$ confidence interval $(\mathrm{Cl}) 1.95-5.61)$ but not in men $(\mathrm{OR}=0.77,95 \%$ Cl 0.37-1.60)
Multivariate logistic regression indicated that, adjusting for age and gender, reporting problems related to a dysfunctional family of origin $(O R=1.51,95 \% \mathrm{Cl} 1.09$ 2.08), a history of sexual abuse ( $O R=1.96,95 \% \mathrm{Cl} 1.27-$ 3.02) and imprisonment of self or other ( $O R=4.60,95 \%$ Cl 2.02-10.49) were each significantly and independently associated with an increased likelihood of a previous history of DSH, while the reporting of problems related to work or school issues remained significantly associated with a decreased likelihood of such a history $(O R=0.56$, $95 \% \mathrm{Cl} 0.35-0.88$ ). The increased likelihood of previous DSH in women that was associated with a history of physical abuse remained significant in the multivariate model (OR=4.10, 95\% Cl 1.64-10.27).

\section{Prospective repetition}

Of the 2287 patients monitored, 361 (16\%) presented to hospital with a further act of DSH during the 2-year study period. Men were more likely than women to repeat $(18 \%$ v. $14 \%$, respectively; age-adjusted $\mathrm{OR}=1.34,95 \% \mathrm{Cl}$ 1.07-1.69). Those with a previous history of DSH were far more likely to repeat than those whose index act was a first occurrence of DSH (29\% v. 9\%, age-adjusted $\mathrm{OR}=4.15,95 \% \mathrm{Cl} 3.20-5.38$ ).

Table 3 compares the frequency and risk of further DSH within the study period between the patients who reported each life event category and those who did not. The reported life events associated with previous DSH were the only ones associated with further hospitaltreated DSH, adjusting for gender, age and previous DSH. Thus, reporting a dysfunctional family of origin, a history of either sexual or physical abuse and imprisonment of self or other were associated with significantly increased risk of repetition, whereas reporting problems relating to work and/or school was associated with a lower risk of repetition. A multivariate model including each of these factors with age, gender and previous DSH indicated that

Table 1. Comparison of those asked about life events in their assessment to those who were not asked

\begin{tabular}{|c|c|c|c|c|}
\hline \multirow[b]{2}{*}{ Characteristic } & \multicolumn{2}{|c|}{ Asked } & \multicolumn{2}{|c|}{ Not asked } \\
\hline & $n$ & $(\%)$ & $n$ & $(\%)$ \\
\hline Males & 655 & $(43)^{\star *}$ & 392 & (51) \\
\hline Age $15-24$ years $^{1}$ & 617 & $(41)$ & 336 & (44) \\
\hline Self-poisoning only & 1213 & $(80)$ & 597 & (78) \\
\hline Alcohol in act & 479 & (31) & 208 & $(27)$ \\
\hline Previous act & 562 & $(42)^{\star *}$ & 208 & (34) \\
\hline Married/cohabiting & 364 & $(25)$ & 142 & $(20)$ \\
\hline Living alone & 244 & $(17)$ & 87 & (13) \\
\hline Low education & 387 & (38) & 132 & (35) \\
\hline Unemployed & 455 & (32) & 189 & (32) \\
\hline History of alcohol abuse & 408 & $(37)$ & 143 & (37) \\
\hline
\end{tabular}

$* * P<0.005$, with Bonferroni adjustment.

Percentages are adjusted for missing values.

1. Median age of those asked $=27$ years; those not asked $=25$ years 
Table 2. The 14 most commonly reported categories of life events and their associated risk of repetition of deliberate self-harm (DSH)

\begin{tabular}{|c|c|c|c|c|c|c|}
\hline Life event category & $\begin{array}{c}\text { Men } \\
(n=1047) \\
\%\end{array}$ & $\begin{array}{c}\text { Women } \\
(n=1240) \\
\%\end{array}$ & $\begin{array}{c}\text { Repeat DSH } \\
\qquad \begin{array}{c}n=770) \\
\%\end{array}\end{array}$ & $\begin{array}{c}\text { First DSH } \\
(n=1173) \\
\%\end{array}$ & Odds ratio 1 & $95 \% \mathrm{Cl}$ \\
\hline Marital/relationship problems & 24 & 28 & 26 & 26 & 0.85 & $0.66-1.10$ \\
\hline Family conflict/current problems ${ }^{2}$ & 22 & 27 & 24 & 27 & 0.91 & $0.70-1.17$ \\
\hline Dysfunctional family of origin & 14 & 16 & 18 & 13 & $1.73^{* * *}$ & $1.27-2.36$ \\
\hline Bereavement/anniversaries & 10 & 11 & 11 & 11 & 0.93 & $0.65-1.31$ \\
\hline Work/school problems & 9 & 8 & 5 & 10 & $0.51 * *$ & $0.32-0.80$ \\
\hline History of sexual abuse ${ }^{2}$ & 3 & 11 & 11 & 5 & $2.34 * * *$ & $1.54-3.55$ \\
\hline History of physical abuse ${ }^{2}$ & 5 & 9 & 11 & 5 & $2.01 * * *$ & $1.33-3.05$ \\
\hline Legal/judicial problems ${ }^{2}$ & 8 & 3 & 7 & 4 & 1.51 & $0.93-2.45$ \\
\hline In prison (self/other) & 5 & 1 & 4 & 1 & $4.80 * * *$ & $2.12-10.88$ \\
\hline
\end{tabular}

${ }^{* *} P<0.01, * * * P<0.001$

The following were mentioned but with insufficient frequency to be included above: unemployment/unable to work; housing/care problems; institutionalised/seeking admission; conflict with neighbours; communication problems; alcohol abuse in others; physical illness in others.

1. Age- and gender-adjusted odds ratio.

2. Significant gender difference in the prevalence of this category of life event.

a dysfunctional family of origin (adjusted OR=1.88, 95\% $\mathrm{Cl} 1.32-2.67$ ), a history of sexual abuse (adjusted $\mathrm{OR}=2.6$, $95 \% \mathrm{Cl} 1.69-4.05)$ and imprisonment of self or other (adjusted $\mathrm{OR}=2.21,95 \% \mathrm{Cl} 1.12-4.40$ ) were independent risk factors for further DSH.

\section{Discussion}

Certain life events, particularly those of an interpersonal nature, are associated with repeated DSH. The picture that emerges of the lives of those who harm themselves will be familiar to those who regularly conduct clinical assessments. A history of being sexually abused (often in childhood) was associated with previous and future DSH, as was reporting a dysfunctional family of origin and the imprisonment of self or other.

Women generally reported more stressors and these were more likely to be internal family problems such as family conflict and pregnancy issues. In contrast, men more often cited problems external to the family, such as legal/judicial problems and imprisonment, although the latter may relate to the fact that the catchment area included three prisons, only one of which catered for female prisoners

The methodology used in this study is necessarily limited, given the self-report nature of the information recorded in patient case notes. In Ireland, psychiatrists routinely acutely assess patients who have harmed themselves, making it more likely that background information is sought and, therefore, is available in the case notes. We found that life events were discussed in two- thirds of the study population, and that those asked and not asked were similar both demographically and clinically.

In general, the factors described by those for whom this was a first attempt were more likely to indicate stresses involved with recent or ongoing interpersonal relationships. They were more likely to cite family conflict, work or school-related problems, or the stress of illness in others, whether physical or psychological. Problems with school or work were more often identified by those who did not repeat DSH, emphasising the protective nature of involvement in education or gainful employment (Whelan, 1992).

The complex processes by which early experiences predispose to self-harm as a response to stress may be best understood in terms of attachment theory (Bowlby, 1980). Suicidal behaviour has been explained as extreme attachment behaviour (Adam, 1994). Dysfunctional family of origin is a general term given for a disruptive early life experience. This was often related to addiction in one or both parents, although the specific category of 'alcohol misuse in others' was not reported frequently in this study, perhaps indicating that it is more the disturbance in family life that is remembered rather than the underlying addictive behaviour. Repeated DSH was not associated with a greater number of reported stressors, although the particular stressors cited by those repeating DSH are more likely to be long-standing. Patients who harm themselves and who present with certain life histories merit selection for services designed to reduce recurrence. 
Table 3. The frequency and risk of further deliberate self-harm (DSH) associated with the 14 life event categories most commonly reported

original papers

\begin{tabular}{|c|c|c|c|c|}
\hline Life event category & \multicolumn{3}{|c|}{ Repeated during study } & $95 \% \mathrm{Cl}$ \\
\hline \multicolumn{5}{|c|}{ Marital/relationship problems } \\
\hline Reported & 73 & (18) & 1.03 & $0.76-1.40$ \\
\hline Not reported & 195 & (17) & & \\
\hline \multicolumn{5}{|c|}{ Family conflict/current problems } \\
\hline Reported & 61 & (16) & 0.89 & $0.65-1.22$ \\
\hline Not reported & 207 & (18) & & \\
\hline \multicolumn{5}{|c|}{ Dysfunctional family of origin } \\
\hline Reported & 62 & $(27)$ & $2.13^{* \star *}$ & $1.53-2.98$ \\
\hline Not reported & 206 & $(16)$ & & \\
\hline \multicolumn{5}{|c|}{ Social isolation/poor supports } \\
\hline Reported & 36 & $(18)$ & 1.06 & $0.72-1.58$ \\
\hline Not reported & 232 & $(17)$ & & \\
\hline \multicolumn{5}{|c|}{ Bereavement/anniversaries } \\
\hline Reported & 29 & $(18)$ & 1.04 & $0.68-1.60$ \\
\hline Not reported & 239 & $(17)$ & & \\
\hline \multicolumn{5}{|c|}{ Work/school problems } \\
\hline Reported & 13 & $(10)$ & $0.53^{*}$ & $0.29-0.96$ \\
\hline Not reported & 255 & (18) & & \\
\hline \multicolumn{5}{|c|}{ History of sexual abuse } \\
\hline Reported & 39 & (34) & $3.07 * * *$ & $2.01-4.69$ \\
\hline Not reported & 229 & $(16)$ & & \\
\hline \multicolumn{5}{|c|}{ History of physical abuse } \\
\hline Reported & 31 & $(27)$ & $1.90 * *$ & $1.22-2.95$ \\
\hline Not reported & 237 & (17) & & \\
\hline \multicolumn{5}{|c|}{ Legal/judicial problems } \\
\hline Reported & 15 & $(18)$ & 0.91 & $0.51-1.63$ \\
\hline Not reported & 253 & (17) & & \\
\hline \multicolumn{5}{|l|}{ Financial problems } \\
\hline Reported & 11 & (14) & 0.70 & $0.36-1.35$ \\
\hline Not reported & 257 & $(18)$ & & \\
\hline \multicolumn{5}{|l|}{ Child related problems } \\
\hline Reported & 20 & $(25)$ & 1.59 & $0.94-2.71$ \\
\hline Not reported & 248 & (17) & & \\
\hline \multicolumn{5}{|c|}{ Suicide/parasuicide model } \\
\hline Reported & 14 & $(22)$ & 1.42 & $0.77-2.62$ \\
\hline Not reported & 254 & (17) & & \\
\hline \multicolumn{5}{|c|}{ Pregnancy related problems } \\
\hline Reported & 5 & $(10)$ & 0.54 & $0.21-1.39$ \\
\hline Not reported & 263 & (18) & & \\
\hline \multicolumn{5}{|l|}{ In prison (self/other) } \\
\hline Reported & 14 & (33) & $2.26^{\star}$ & $1.16-4.40$ \\
\hline Not reported & 254 & (17) & & \\
\hline
\end{tabular}

${ }^{*} P<0.05 ;{ }^{* *} P<0.01 ; * * * P<0.001$

Percentages are adjusted for missing values.

1. Odds ratio adjusted for age, gender and previous DSH

\section{Acknowledgements}

This paper is dedicated to the late Dr Michael J. Kelleher, Founding Director of the National Suicide Research Foundation. We thank all those who contributed to the study. We also acknowledge the many hospital, health board and prison personnel who have facilitated and supported the study.

\section{Declaration of interest}

The work of the National Suicide Research Foundation has been made possible through the support of the Irish Government's Department of Health and Children, the Southern and Mid-Western Health Boards and a unit grant from the Irish Health Research Board. 


\section{References}

ADAM, K. S. (1994) Suicidal behaviour support and suicide. Acta Psychiatrica and attachment. In Attachment in Scandinavica Supplementum, 377 $65-72$. Adults: Clinical and Developmental Perspectives(eds M. B. Sperling \&W. H. Berman), pp. 275-298. NewYork: Guilford Press.

LINCOLN, Y. S. \& GUBA, E. G. (1985) Naturalistic Inquiry. Beverly Hills, CA: Sage.

BOWLBY, J. (1980) Attachment and Loss: Loss, Separation and Depression. NewYork: Basic Books.

PLATT, S., BILLE-BRAHE, U., KERKHOF, A., et al (1992) Parasuicide in Europe: TheWorld Health Organization/Euro Multicentre Study on parasuicide. I.

CENTRAL STATISTICS OFFICE (1997) Census 1996: volumes I \& II. Cork: Central Statistics Office. 